entre endometriose, dismenorréia e spotting pré-menstrual; associação significativa entre endometriose e dispareunia; e uma associação forte entre endometriose e massa anexial. Os tipos de lesões mais freqüentes, (80,9\% dos casos), foram as lesões atípicas e os locais de implantação mais freqüentes foram os ligamentos útero-sacros e os ovários. O grau de endometriose mais freqüente foi o grau I (52,7\% dos casos). A biópsia foi confirmada em $80 \%$ dos casos suspeitados pela videolaparoscopia.

Conclusão: A endometriose continua sendo uma doença enigmática que afeta pacientes na idade reprodutiva, em sua grande maioria, e que apresenta associação ou tendência à associação com grande parte dos sintomas clínicos, com a macroscopia das lesões, mas no entanto, depende intrinsecamente do resultado da biópsia. Assim sendo, a laparoscopia é um bom método para o diagnóstico de endometriose pélvica e na presença de sinais e sintomas clínicos que levem à suspeita da doença, a confirmação histológica ocorreu em $80 \%$ dos casos.

Palavras-chave: Endometriose. Laparoscopia. Algia pélvica. Massa anexial.

\title{
Avaliação da Mobilidade do Colo Vesical com Ultra-Sonografia Via Vaginal em Mulheres com
}

\section{Perda de Urina aos Esforços}

Autor: Edson O’Dwyer Júnior

Orientador: Prof. Dr. José de Souza Costa

Tese apresentada ao Curso de Mestrado em Assistência Materno Infantil da Faculdade de Medicina da Universidade Federal da Bahia em 26 de janeiro de 2000.

Introdução: A queixa de perda de urina aos esforços é freqüente em nosso meio, e o diagnóstico, na maioria das vezes, é feito baseado apenas em critérios clínicos, levando a um indice elevado de falha terapêutica. A ultra-sonografia (USG) vem sendo recomendada para avaliar a mobilidade do colo vesical em mulheres com queixa de perda de urina aos esforços, entretanto seu uso não é consensual.

Objetivos: Avaliar a posição do colo vesical em repouso e ao esforço, com USG via vaginal, em mulheres com queixa de perda de urina aos esforços. Avaliar diferenças na mobilidade do colo vesical entre mulheres com queixa de perda de urina aos esforços e com diferentes diagnósticos por estudo urodinâmico.

Desenho do estudo: Estudo descritivo com 39 pacientes com queixa de perda de urina aos esforços, matriculadas no Ambulatório de Uroginecologia do Hospital Universitário Prof. Edgard Santos, da Universidade Federal da Bahia, entre outubro de 1997 e setembro de 1999. Material e métodos: Trinta e nove pacientes com queixa de perda de urina aos esforços foram submetidas a anamnese, exame físico, avaliação da mobilidade do colo vesical com ultra-sonografia via vaginal e a estu- do urodinâmico. Além da avaliação da posição e da mobilidade do colo vesical, foi feita comparação entre as medidas da USG e os diferentes diagnósticos urodinâmicos.

Resultados: Das 39 pacientes, 4 tiveram avaliação ultrasonográfica inconclusiva devido a anormalidades anatômicas. As medidas da distância do colo vesical ao limite inferior da sinfise púbica foram $+0,85 \mathrm{~mm}$ repouso e - $10,70 \mathrm{~mm}$ ao esforço, com deslocamento de 13,45 mm. Não houve diferença estatisticamente significante quando se comparou a posição e a mobilidade do colo vesical entre mulheres com diferentes diagnósticos urodinâmicos.

Conclusões: Neste estudo a mobilidade do colo vesical em pacientes com incontinência urinária correspondeu à relatada na literatura. Não houve diferença na posição e na mobilidade do colo vesical entre pacientes com queixa de perda de urina aos esforços e diferentes diagnósticos urodinâmicos.

Palavras-chave: Incontinência urinária de esforço. Ultra-sonografia. Colo vesical. Estudo urodinâmico.

Estudo da associação entre parâmetros anatomopatológicos de prognóstico e a dopplerfluxometria no câncer de mama

Autor: Henrique Moraes Salvador Silva

Tese de livre docência apresentada à disciplina de Ginecologia da Faculdade de Medicina de Valença em 31 de março de 2000.

O câncer de mama apresenta manifestações clínicas variáveis e sabe-se que os fatores prognósticos apre- sentam influência na evolução da doença. O status axilar e o grau histológico (Bloom \& Richardson) re- 
presentam fatores prognosticos estabelecidos na literatura, entretanto outros fatores tem sido estudados. Os princípios do Doppler no câncer de mama baseiam-se no aumento da vascularização e da neovascularização nas neoplasias. Os objetivos deste estudo foram comparar o padrão vascular das neoplasias, segundo a Tabela Mater Dei, com fatores prognósticos clássicos (status axilar e grau histológico), estabelecer grupos de pacientes que não se beneficiariam de uma dissecção axilar e identificar tumores de comportamento mais agressivo, que mereceriam tratamento sistêmico neoadjuvante mesmo em estádios precoces. Trata-se de um estudo clínico, duplo-cego e associativo, através da análise de 53 pacientes portadoras de câncer de mama, detectáveis ao ultra-som. Classificouse os tumores de acordo com os critérios dopplerfluxométricos da Tabela Mater Dei e posteriomente as pacientes foram encaminhadas ao tratamento cirúrgico e estudo anatomopatológico (status axilar e grau histológico), considerados padrão ouro. Seguiu-se um estudo de associação entre estes fatores clássicos e os achados dopplerfluxométricos. Os resultados, quando comparados Doppler tipos A e D com o status axilar, foram : $\mathrm{S}=85,0 \%, \mathrm{E}=82.4 \%, \mathrm{VPP}=85,0 \%$ e $\mathrm{VPN}=82.4 \%$. Já na associação de Doppler tipo A e D com o grau histológico I e III obtivemos: $\mathrm{S}=90,0 \%, \mathrm{E}=69.2 \%$, $\mathrm{VPP}=69.2 \%$ e VPN=90,0\%. A avaliação dopplerfluxométrica mostrou ser um método simples, reprodutivel, não-invasivo e disponivel em vários serviços. Concluise que o estudo Doppler pode se constituir um fator prognóstico para o câncer de mama, quando a análise dos tumores segue a classificação da Tabela Mater Dei para os tipos A e D.

Palavras-chave: Mama: câncer. Dopplervelocimetria. Câncer: prognóstico.

\section{CURSO/CONCURSO PARA OBTENÇÃO DO TÍTULO DE HABILITAÇÃO EM ULTRA- SONOGRAFIA}

\section{Informações na Federada do seu Estado}

\section{Inscrições: 26 de Junho a 29 de Setembro de 2000}

\section{Curso: 10 e 11 de Novembro de 2000}

\section{Concurso: 12 de Novembro de 2000}

